Original Research Paper

\title{
Systematic Interpretation of the Factors of Federal Sustainability and Socio-Political Security of a Constituent State of a Federation
}

\author{
Yuliia Anatol'evna Matafonova \\ Department of Public, Municipal Management and Politics, \\ Transbaikal State University, Chita, Zabaikalsky Krai, Russia
}

\author{
Article history \\ Received: 27-11-2015 \\ Revised: 24-02-2016 \\ Accepted: 25-02-2016 \\ Email: mega-yulya@mail.ru
}

\begin{abstract}
The article deals with a constituent state of a federation, both a spatial unit of medium size, being an element of the federal system and as a local system having its own institutional, regulatory, cultural, ideological and communicative characteristics. In this article, we attempt to equate to some extent the federal sustainability and socio-political security of a constituent state of a federation. We propose to consider the federal sustainability not only as a federal system's property, but also as a set of intrinsic characteristics of the political and territorial space of a constituent state, contributing to the implementation of the main objectives of federalism and the federal structure-to promote the vital interests of its population. In accordance with the methodology of the system approach and role-based method of description of the processes occurring in the political system, used by Almond and Powell, we break up the factors of federal sustainability and socio-political security of a constituent state of a federation into five groups: Institutional, regulatory, communicative, ideological and cultural.
\end{abstract}

Keywords: Federal Sustainability, Socio-Political Security, Constituent State of a Federation, Systematic Approach

\section{Introduction}

In a federal state, it is particularly important to ensure security. Due to the nature of a federal state as a special system of the political and territorial space organization and management, the security system of a federal state is structurally made up of regional security systems of its constituent states, because a breach of one constituent state's security threatens the existence of the entire federation.

In modern political science, there are a number of methodological approaches to the study of the essence of the socio-political security and stability of a state and a political system.

One of the generally recognized models is the Political System Stability Index (PSSI), developed by (Haendel et al., 1975). It is based on the method of aggregated statistical data used for the detection of positive or negative trends in a country. The specificity of the Political System Stability Index resides in identifying precise causal relationships that are based on econometric and other objective indicators of the political and social environment. The indicators are divided into three sub-indices: The socio-economic, social conflict and governmental indices. However, being political risk researchers, these scientists focus on the study of factors and events that lead to a change in the business environment (Haendel et al., 1975).

Therefore, to study the federal stability and sociopolitical security of a constituent state of a federation, we propose to use the systematic approach methodology, which allows taking into account the specifics of a federal political and territorial space.

\section{Materials and Methods}

Since a constituent state of a federation is part of the federal political system and in terms of the structure and the political and territorial organization of the federation is its element, we offer to apply Almond's and Powell's methodology of the structural and functional analysis to the determination of the factors of its stability and security (Almond and Powell, 1988). This approach will allow us to break up the factors of federal stability and 
socio-political security of a constituent state of a federation in accordance with the role-based method for description of the processes taking place in the political system into 5 groups: Institutional, regulatory, ideological, communicative and cultural. In terms of ensuring the stability and security, each of the subsystems has its own peculiar features.

\section{Results}

A constituent state of a federation is a political and territorial entity, part of a federation, having rights and responsibilities in relation to the federation. The Constitution of the Russian Federation considers a constituent state of the Russian Federation as a form of territorial democracy in a state of law.

Modern scholars often identify the concepts "constituent state" and "region". A constituent state is a political and territorial space, political and territorial unit of a federation. A region is understood in a broader sense. It may be considered as an administrative and territorial unit, a historical and cultural community, a geopolitical space.

In our study, we identify these concepts and base on the definition of Markusen who considered a region to be a historically evolving, compact territorial community, comprising physical, socioeconomic, political and cultural environment, as well as a spatial structure different from other regions and territorial units, such as a city or a nation (Markusen, 1987).

The institutional framework of a constituent state is based on the principle of constitutional and legal delimitation of the sovereignty of the federation and the self-government of its constituent states. According to the dualistic doctrine, the power of constituent states does not have the fullness of state sovereignty, but is involved in the formation of "shared sovereignty", which is derived from "agreed decision of local and central authorities" (Yashchenko, 1912). The concept of divisibility of sovereignty has not lost its relevance in the present time, as well. Watts (2008) points out that structural feature of the federation is the availability of federal governments of the two levels-the central one and that of the subject of the federation, exercising power over the citizens directly. Only combination of powers yields the nationwide power, representing a federal state in its entirety and being a carrier of national sovereignty. Harmony of the federal system follows from the constant interaction of the preserved autonomy of each member and their voluntary commitment to the implementation of the whole.

Such an approach to the explanation of sovereignty in a federal state is associated with socio-political factors in the formation of the federation. If in the USA the federation was formed "from below" (by a politically active society), then it is quite logical for the federal government to perform functions assigned to it by the constituent state. In Russia, on the contrary, throughout the entire history "conversions from the top" are observed, in particular the federal structure was initiated either by "enlightened monarchy", or by the modern authority in connection with the crisis of the obsolete unitary system.

Despite the debatable nature of the problem, it is indisputable that in a federal state sovereignty acquires a new content, since a problem comes to light relating to the separation of authoritative powers between the state and its constituents.

Sovereignty of a constituent state is specific and is associated with the delimitation of powers and the matters of exclusive jurisdiction of the constituent states of the federation. In some federations, constituent states are granted the right to secede freely from the federation. For example, the right of withdrawal (secession) is enshrined in the 1994 Federal Constitution of Ethiopia, which, however, is not granted to federated states, but to nations, ethnicities, nationalities. Therefore, a constituent state of a classical federation cannot retrieve at its own discretion the sovereign rights as it is bound with obliging relations to other constituent states of the federation and the federation's fate is in the hands of the entire population of the union state, but not of each individual constituent state. A federal union creates institutional order, which exists independently of the will of its members and which can be changed only by a majority vote.

The distribution of powers between different levels of a federal state is built in such a way that the state itself (the Center) is granted the unfettered external sovereignty and part of the internal sovereignty and constituent states of the federation are granted some attributes of the internal sovereignty-self-government.

The institutional framework of constituent states is represented by the public authorities of the constituent states. In a narrow sense, the institutional subsystem of a constituent state of a federation includes only institutions, organizations and structures created for administration-the public authorities. In broad terms, the basic institutions of a constituent state can be considered as the totality of political institutions, agencies, social organizations, acting in the political and territorial space of the constituent state of a federation.

A constituent state has the constituent power, which is expressed in the adoption of the base law of the constituent state (a Constitution, a Charter) and establishment of an independent system of public authorities in accordance with the federal law. However, the mere existence of public authorities is not able to provide sustainability and security.

To ensure federal sustainability and security, the constituent state should have a system of public 
authorities that can efficiently and effectively address the issues of regional governance.

In terms of the political analysis, the underlying institutional factor of federal sustainability and sociopolitical security is "proper" organization and functioning of the public authorities of the constituent state. A priori, federalism is based on the principles providing the following institutional order: The principle of legality and constitutionality, the principle of horizontal and vertical separation of powers, the principle of subsidiarity, the principle of division of powers and others.

While at the level of the federation, in institutional terms the presence of a second parliamentary chamber contributes to maintaining the federal political system, at the level of the constituent state of a federation the system of the population representation in the legislative body of the constituent state, recognized by the majority, will be the fundamental institutional factor of its sustainability and security. In this perspective, the factors of federal sustainability and socio-political security assurance are directly related to the existence of a party system, the electoral institution, the institution of local self-government and the democratic majority institution on the territory of the constituent state.

Functioning of parties and party systems in the federal states has some specifics. Based on the practice of party construction in the federations, we can distinguish two generalized models of party systems. The first model-a centralized one-is widespread in most federal systems, where political parties are national (federal) associations having representative offices in the constituent states of the federation. The second model-a decentralized one-implies that party organizations at the level of the federation constituents and at the local government level are autonomous political alliances. An example of parties operating only in certain constituent states of the federation can be the Basque Nationalist Party ("Basque Solidarity") in the Basque Country in Spain or the Bloc Québécois in the Canadian province of Quebec.

Being a basis of the democratic process, the parties in the political and territorial space of the federation and its constituents not only carry out the function of representing the interests of the population. Their functioning can strengthen or undermine the stability of the constituent state of a federation.

Riker (1975) assumed that in a federal state the party system in conjunction with the second chamber of parliament, the executive and judicial branches of the federal power performs the function of maintaining a federated transaction-preserving federalism as a principle of the state structure. In the context of the American decentralized party system local party organizations exert a significant impact on the national political process. Local party organizations put forward their own candidates for elective office independently, thus affecting the party's policy. Available separate party elections at the national level, the level of the federation constituents-the states and the local government level allow Riker to doubt the continuity of the political course and talk about the prevalence of trade between the Centre and the states. Comparing the existing federal systems, Riker deduces a direct correlation between the configuration of the party system and the stability of the federal state. If federal parties control the parties of the federal constituents (regional offices, branches), this increases the stability of the federation. However, there is the danger of absolute priority given to centralization of the federal system and its transformation into a unitary one. In the absence of such control by the central apparatus of the party the level of decentralization increases and a threat to the political and territorial integrity of the federation occurs.

The institution of elections and the democratic majority have no less influence on the stability of the federation. Elections are a fundamental institution of formation of authorities at all levels, the basic institution of a democratic political system. The issue of relationship between democracy and forms of political and territorial structure is debatable. Some researchers argue that there is no direct relationship between democracy and a federal territorial structure, noting that under the unitary structure of the state democratic institutions can be developed. In accordance with the modern trends of the unitary states' development, one cannot but agree with this statement. However, a federal political and territorial arrangement is not possible without the institution of elections. The very structure of a federal state provides for the principle of election and representation. Zakharov (2003) points out: “... regardless of the conditions, place and time, democracy, civil institutions and federalism are mutually stipulated by each other. Federalist model degenerates into a farce where the traditions of civic-mindedness are weak, democratic institutions do not work and the state holds an absolute priority over the individual". Consequently, no federal structure will be sustainable without democratic foundations: The practice of coordination of interests, democratic political culture, civil society and the institution of elections.

Periodic elections in the constituent of a federal state provide for the process of natural renovation (rotation) in the membership of the bodies of power at the regional and local levels.

The institute of democratic majority operates to make the most important decisions for the state and society within the federation and the federal constituent. Both the stability of the federation as a whole and the stability of its constituent states depend on its functioning. 
The principle of democratic majority is a natural consequence of the multi-party institution in action. In the context of a society divided into independent parties (or states, land, etc.), which are not subordinated in a hierarchical way, but have equal rights, there is an objective basis for adding these separate social positions, votes, opinions to form the overall decision.

Action of the institution of democratic majority is expressed, first of all, in the order of amendment of the most important documents of the state, such as the Constitution. Thus, Amendments to the United States Constitution-the basic law of the country-are undoubtedly adopted if they are supported by legislative bodies and conventions of at least three-fourths of the states, that is, the democratic majority of equitable political constituents forming the state spoke in favor of these amendments. Similar provisions exist in other countries with a federal political system, as well.

However, the institution of democratic majority in the federal states also has its own specifics. Canadian researcher Whitaker drew attention to the difference in the functioning of democratic institutions in the unitary and federal systems. In the unitary states with political democracy the democratic institutions are based on the majority whose will is expressed in the government formed on a population basis, the legislative and the judicial bodies. In the federal states institutions of democracy have a different genetic nature. According to Whitaker, in the federation institutions of democracy are focused not only on the majority, but also on the protection of the interests of the minority, whether it is a constituent state of the federation, ethnic or religious group (Whitaker, 1992).

Thus, the will of the majority in the federal state and its constituents is transformed into the more general category of sovereignty and phenomenon of democratic citizenship. It is difficult to disagree with these judgments, because the idea of federalism apriori is based on the combination of the principle of the state integrity and self-determination principle within the political-territorial limits of the federal state, the latter principle implying preservation of ethnic, linguistic, socio-cultural, religious and other diversity.

The institutional subsystem of a constituent state largely determines the level of socio-political security and federal sustainability of the constituent state. The analysis of the institutional factors of stability and security of a constituent state of a federation is multidimensional, as these factors should include not only the structural and functional characteristics of the regional authorities, but also the totality of political institutions, agencies and social organizations operating in the political and territorial space of the constituent state of a federation.
Both for a federation as a whole and for a constituent state of the federation, the institutional subsystem is not just the structure, the frame and the combination of certain socio-political phenomena and processes based on repeated and sustained collective behavior, leading to the formation of universal norms of the federal state system (Matafonova, 2014).

The regulatory subsystem of a constituent state of a federation includes a set of fixed (constitutional and legal) and ambulatory standards determining its functioning as a political and territorial space. The regulatory framework is no less important than the institutional one. By virtue of the federation sovereignty and the self-government of its constituent states identified by us, the regulatory subsystem of a constituent state of a federation is included in the federal one: The determining regulations for the constituent state are the federal ones. The analysis of the factors of federal sustainability and socio-political security of a constituent state must be based on the provisions of the Constitution and federal laws and regulations. Based on the practice of the federative legislative development of Russia, the threshold regulatory factors of sustainability and socio-political security of both the federation as a whole and its constituent states are orderliness, consistency and absence of potential conflicts in the regulatory framework of the arrayed federal relations. In our view, the regulatory factors ensuring the federal sustainability and socio-political security of constituent states of a federation should be broken up into two groups. The first group-the regulatory factors external to a constituent state of a federation-is related to the constitutional principles of federal relations, the regulations of the Center and the established order of the power delineation between the federal and regional levels of government. The second group-the intraregional factors-is based on political decisions taken by the authorities of the constituent state. In the second group, the threshold criteria of ensuring sustainability and socio-political security will be adequacy, timeliness of adoption of legal acts, their compliance with the needs of the society, their orientation to solving problems specific of a particular constituent state.

Ambulatory standards also impact the functioning of the federation and its constituent states. They can be expressed in terms of historical and national traditions and customs, ethical and moral aspects of the activity of the regional authorities' representatives.

The communicative subsystem in Almond's and Powell's theory represents the totality of relations and forms of interaction developing between classes, groups, nations, individuals about their participation in the organization, implementation and development of the 
political power in connection with the development and implementation of the policy.

The communicative subsystem of a constituent state of a federation consists of two levels: The first level is related to the delineation of competences and powers between the federal center and the constituent states (federative relations); the second one is linked to the interaction of authorities of the constituent state with municipalities, socio-political organizations and the population. Accordingly, the communicative factors of stability and socio-political security of a constituent state should be divided into two groups.

A priori, as a property of a federal political system, resistance is the basis of the mechanism of delineation of competencies and powers, recognized by the constituent states. Therefore, the first group of communicative factors is directly related to the effective and optimal for a particular federative mechanism delineation of powers between the Center and regions.

An important factor of ensuring the intraregional federal sustainability and secure socio-political development is the communicative capabilities of the public authorities of the constituent state of a federation. In this case, the optimal option for regional authorities is to build a communication model based on the universal scheme of interaction of Easton, which includes 4 major phases: Input, conversion, output and feedback (Easton, 1979). Adaptability, openness and responsiveness are the keys to effective communication between the government and the society of a constituent state.

Communicative factors providing federal sustainability and socio-political security of a constituent state of a federation can be analyzed both by the universal model of Easton and through the use of the Data Envelopment Analysis (DEA) method, based on the representation of the region (constituent state) as the center of decision-making, which employs the resources of society-the inputs-to achieve social outcomes-the output (O’Donnell and Westhuizen, 2002).

Communicative factors of securing federal sustainability of a constituent state of a federation should be considered from a broad perspective, not just as a mechanism for the relationship between the regional government and the society, but also as a timely response to the socio-economic needs of the population, as a process of political decision-making at the level of the constituent state, aimed at achieving a decent standard of social welfare. In the conditions of the Russian Federation, budget expenditures for the provision of certain public amenities are considered the input and the achieved indexes characterizing the living standards are considered the output (Akhremenko, 2013).

From the point of view of the theory of federalism, the ideological subsystem in a federal state and in its political and territorial units (constituent states) acts as the value-related concept, which allows maintaining the integrity of the federation.

The ideological factors at the level of the federal state are linked to the national identity and at the level of its constituent states-to the national, regional and local identity of the population.

Farukshin (2013) distinguished two aspects in the population's attitude to federalism: The attitude to the federal form of the state structure in general and the approach of the population to the choice of the object of primary support, which can be either the entire federation, or its individual constituent state, as well as to the assessment of certain institutions of federalism.

To ensure the federal sustainability of a constituent state, the population should identify themselves both with the federation as a whole and with the political and territorial entity (the constituent state), in the territory of which they reside. The deviation in one direction or another, as a rule, leads to non-constructive understanding of the federation doctrine-imbalance and enhancement of the centripetal (or centrifugal) trend.

Based on the culturological understanding of federalism and foreign experience in legislative development of a federation, some researchers argue that the focus of the preferences and identity of the population either on the federation or on the constituent state determines the institutional design of the federal structure. If the loyalty of the population to the constituent state of the federation prevails over the loyalty to the federal state as a whole, the likelihood of a federal system more decentralized administratively and fiscally increases (McKay, 2001).

The integrating factor of a federal system as a whole is the cultural subsystem. In the theory by Almond and Powell, it is a system of rooted patterns (stereotypes) of political views, values and political behavior, typical for this society.

In recent years, researchers have increasingly been noting the need for the cultural content of federalism and the predisposition of certain culture bearers to a special"federalist"-type of social relations (Zakharov, 2003). Moreover, the presence of a federalist culture is seen as a necessary criterion for true federalism (Verney, 1995). The general culture is a core, a basis of a federal state, ensuring the federation stability. These provisions are valid for assessing the sustainability of the constituent state of the federation.

The cultural factors of federal sustainability at the level of a constituent state are associated with the values, traditions, habits, interests, self-organization experiences of citizens and their socio-political activity. It is no coincidence that Vincent Ostrom defined federalism as an ideology of a truly self-governing society, an alternative to a centralized power vertical and a homogeneous society. The low level of interest and socio-political 
activity of the population of a constituent state of a federation slows down the process of formation of a civil society and generates socio-political phenomena that violate the rule of law and the established order and undermine the federalism basic principles. The activities of regional authorities in achieving the sustainable development and socio-political security can be effective only if there are certain types of the socio-political activity of the local population.

\section{Discussion}

Among multiple areas and methods for research of modern federal states the systemic approach methodology of is increasingly used. The federal state is regarded by researchers as a complex self-organizing social system, possessing characteristics such as integrity, transparency, hierarchy, structuredness, emergence, indivisibility, inherency, expediency, etc. (Gligich-Zolotareva, 2013). Stability is an essential feature of a federal system. Since the basis of the structural organization of a federal state is formed by the territorial entities-constituent states of the federation, the stability of the federal system as a whole depends on the stability of its constituents.

The systematic interpretation has allowed us to identify and delineate the threshold contours of the factors of federal sustainability and socio-political security of a constituent state of a federation. Based on the structural and functional analysis, we broke up these factors into 5 groups: Institutional, regulatory, communicative, ideological and cultural.

Based on the methodological approach, we have considered a constituent state of a federation as a medium-size spatial partial unit of a federative system, the political and social capacity of which depends on the territory, population and federative organization of the political and territorial space.

As part of a larger system, a constituent state is influenced by the federation. In this case, it can be considered as a local system, which has its own institutional, regulatory, cultural, ideological and communicative characteristics. The specificity of these characteristics comprises the real (not proclaimed) socio-political status of the constituent state and allows determining the level of its federal sustainability and socio-political security. Ensuring the sustainability of the constituent state results in the sustainability of the federation.

The category of 'sustainability' is studied in sufficient detail in the exact sciences and described in terms of the general theory of systems and synergetic approach. However, in the political science it is represented fragmentarily, especially in relation to the constituent of a federal state.
We offer to introduce such notion into the theory of federalism as federal sustainability, which is conditioned by the necessity of an integrated interdisciplinary approach to the study of not only federal political systems, but also their constituent entities.

The classical theory of sustainability considers the stability of the system as its ability to return to the state of a steady of equilibrium after removing disturbance that had broken this equilibrium.

In the politological discourse researchers have linked the concept of sustainability with such definitions as political stability and permanence. Stability serves as a category characterizing only those political processes and phenomena, which undergo variations. Permanence means maintaining political objects, phenomena and processes in the initial state. Sustainability is defined as the ability to restrain changes of political institutions, processes within the previously known boundaries.

Accordingly, the concepts of 'stability' and 'sustainability' in the politological discourse cannot be considered as identical ones, especially in relation to a federal political system and its constituent entities.

Most interpretations of political stability are based on its relationship with the dynamics of the political system.

Stability of a federal state is associated with the internal content and logic of the federal system development, with its structure and procedure of interaction between its component parts (the federation and its constituents), with parameters and direction of their joint motion and controlled changes.

The content of the stability of a constituent of a federal state is similar to the content of the stability of the entire federal system and can be defined as its ability to maintain a dynamic balance within the established institutions, norms and traditions in the long run. If the federal system (or a constituent state of the federation) violates the scope of identity in the course of its operation, i.e., comes into conflict with its own nature-the foundations of the federal statehood, they lose stability.

The concepts of 'stability' and 'permanence' of a federal system serve as qualitative characteristics of the political process within the political and territorial boundaries of the federation (or a constituent state) and allow determining its direction. The concept of sustainability does not contain any indication of a particular quality of the process or condition. Both a destructive process and a creative one can be sustainable. Sustainability does not necessarily mean permanence, although it may include this as a special case. Sustainability of the political system is characterized by the ability of operating actors to retain changes within the specified framework; it is understood as the capability of the system to restore the disturbed equilibrium Sustainability of the federal system is 
determined by its political and territorial organization and relationships 'federation-constituent states of the federation' and balances on the verge of centralization and decentralization, it includes both centrifugal and centripetal processes.

Vital capacity (sustainability) of the system is relative; it exists only in relation to a specific predetermined environment. Federal sustainability cannot be interpreted as an absolute category, it is not universal. Federal sustainability is always filled with specific content, it exists for a particular federal state, which combines the principles of centralization and decentralization in a special way inherent only in this state; it embodies the contractual elements of federalism in its own way. A priori, federalism is a result of compromise and agreement. Modern federalism proceeds from the need for practical solutions to political, social and economic problems on the basis of the principles of subsidiarity, the constitutional and legal delimitation of the sovereignty of the federation and sovereignty of its constituents, rule of law and constitutionality. These principles can be considered fundamental, because each of them reveals the essence of federalism, which is based on the consent (agreement).

Sustainability of the system depends on the sustainability of all its constituent entities and accordingly, sustainability of a federal state depends on the sustainability of its constituent structural units-the constituent states of the federation. Federal sustainability is a political category, characterizing the principles of mutual relations between the federal center and a constituent state of the federation; it is political and territorial sustainability of the federal state as a whole and sustainability of a separate entity within the federation.

A constituent state of the federation not only implements the general federal will but also creates its own system of sustainable and safe regional development, capable of defending the vital interests of the individual and society of a given political and territorial space.

Thus, the concept of 'federal sustainability' can be used to characterize the federated state as a whole (federal political system) and the constituent state of the federation as a mesosystem included in the nation-wide system, but having special features.

\section{Conclusion}

Thus, we have considered the federal sustainability from two perspectives: As a property of a federal state and a federal system as a whole and also as a set of intrinsic characteristics of the political and territorial space of a constituent state of a federation, contributing to the implementation of the main objective of federalism and the federal structure-to promote the vital interests of its population.

On the basis of factors outlined in the article we think appropriate to consider the federal sustainability of a constituent state of the federation by distinguishing its two main components:

- External sustainability (existing outside the constituent state) which depends on the 'place' of the constituent in the federal political environment, on the relationship established between the Federation and its constituent entities, on the principles underlying the delimitation of matters of authority and competences, the distance from the Centre, etc

- Internal sustainability (existing inside the constituent state) as a set of intrinsic characteristics of the political and territorial space of the constituent state of the federation, enabling to ensure its viability through the implementation of the vital interests of its population. In this case, sustainability involves the fulfilment of the main functions by the constituent state of the federation, as a mesosystem, in respect of the federal government and in respect of the population

\section{Acknowledgement}

Special thanks to our colleagues, assisting in the study and to the leadership of the Transbaikal State University.

\section{Funding Information}

This article was written as part of the research "Providing the Secure Socio-Political Development of a Near-Border Constituent State of the Russian Federation-Zabaikalsky Krai”. The study was supported by the grant of the President of the Russian Federation for the governmental financial support of young Russian scientists; a unique identifier of the applied research is MK-7134.2015.6.

\section{Ethics}

The authors have no conflicts of interest in the development of the research and publication of this article.

\section{References}

Akhremenko, A., 2013. Public sector efficiency in Russian regions: 2008-2011. National Research University.

Almond, G. and G. Powell, 1988. Comparative Politics Today: A World View. 4th Edn., Scott, Glenview, ISBN-10: 067339705X, pp: 596. 
Easton, D., 1979. A Framework for Political Analysis. 1st Edn., University of Chicago Press, Chicago, ISBN-10: 0226180158, pp: 142.

Farukshin, M.K., 2013. Public support as a basis for the stability of federalism. Uchenye Zapiski Kazanskogo Univ., 155: 243-248.

Gligich-Zolotareva, M.V., 2013. The 'pendulum' of federalism. Nota Bene: Problems Polit. Society, 4: 59-81. DOI: 10.7256/2306-0158.2013.4.581

Haendel, D., G.T. West and R.G. Meadow, 1975. Overseas Investment and Political Risk. 1st Edn., Foreign Policy Research Institute, Philadelphia, ASIN: B007ESQPA0, pp: 83.

Markusen, A.R., 1987. Regions: The Economics and Politics of Territory. 1st Edn., Rowman and Littlefield, New Jersey, ISBN-10: 0847673944, pp: 304.

Matafonova, Y.A., 2014. Management of a federative state: Basic institutions of a federative system. Vlast, 11: 133-136.

McKay, D.H., 2001. Designing Europe: Comparative Lessons from the Federal Experience 1st Edn., Oxford University Press, Oxford, ISBN-10: 0199242135, pp: 167.
O'Donnell, C. and G. Westhuizen, 2002. Regional comparisons of banking performance in South Africa. South Afr. J. Econom., 70: 224-240. DOI: $10.1111 / \mathrm{j} .1813-6982.2002 . t b 01301 . x$

Riker, W.H., 1975. Federalism, in Greenstein, F. I. and Polsby. Handbook of Political Sci.: Government Institutions and Processes, MA: Addision Wesley, ISBN: 0201026058, 9780201026054 5: 93-172.

Verney, D., 1995. Federalism, federative systems and federations: The United States, Canada and India. J. Federalism, 25: 81-97.

Watts, R.L., 2008. Comparing Federal Systems. 3rd Edn., School of Policy Studies, Queen's University, Montréal, ISBN-10: 1553391888, pp: 205.

Whitaker, R., 1992. Sovereign Idea: Essays on Canada as a Democratic Community. 1st Edn., McGillQueen's Press-MQUP, Montreal, ISBN-10: 0773508414, pp: 337.

Yashchenko, A.S., 1912. Theory of federalism: The experience of the synthetic theory of state and law: Reprint copy. Russian.

Zakharov, A.E., 2003. Pluribus Unum: Modern Federalism Essays. 1st Edn., Moscow School of Political Studies, Moscow, ISBN-10: 5-93895-041-4, pp: 192. 